\title{
nUกU3ヒL3U乙 UกUヒ乙
}

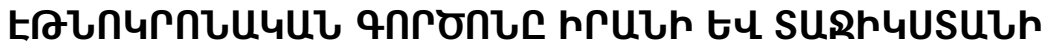

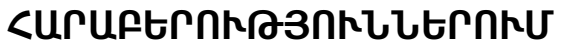

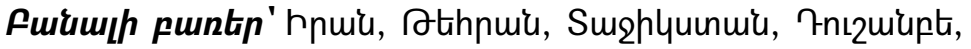

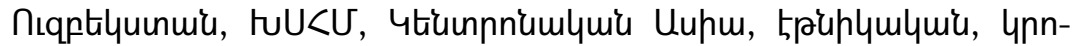
umlumi, humuptipnıpniüutip:

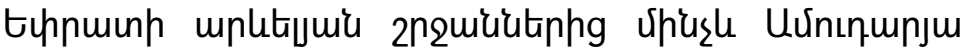

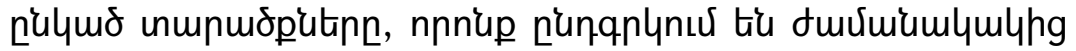

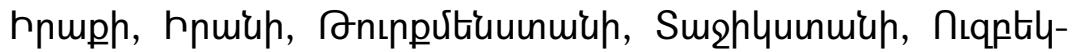

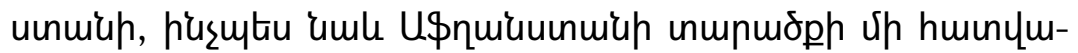

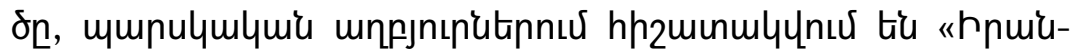

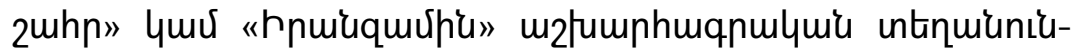

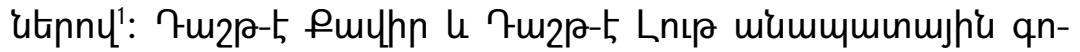

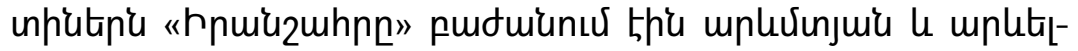

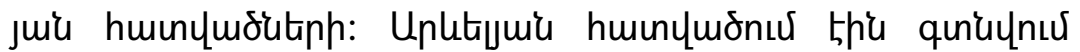

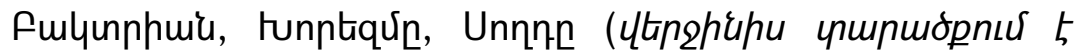

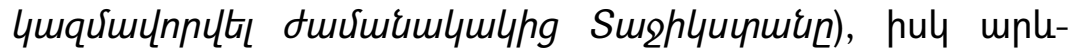

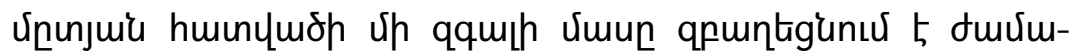
umlymlihg hpuiuh unupurpp:

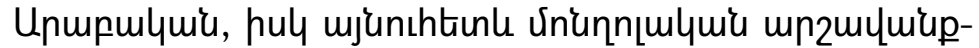

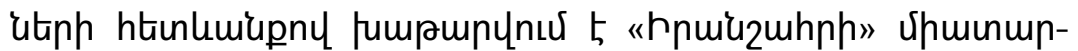

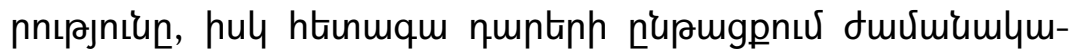

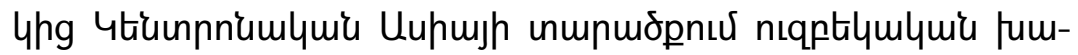

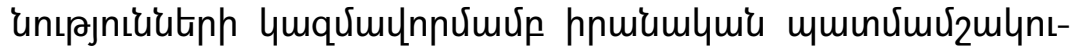

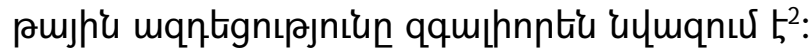

${ }^{1}$ Christensen P., The Decline of Iranshahr, University of Copenhagen, 1993, p. 15.

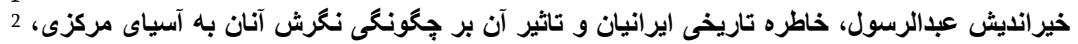

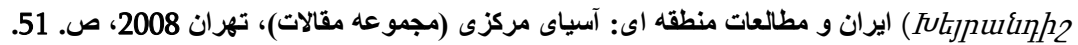
268 


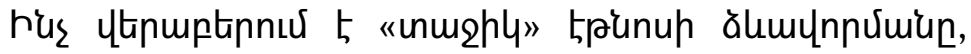

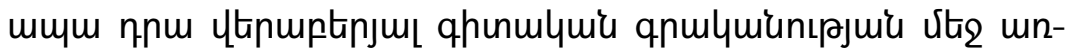

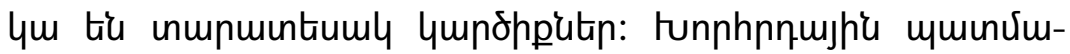

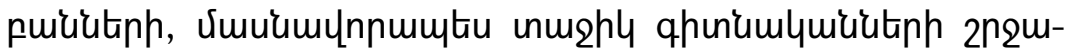

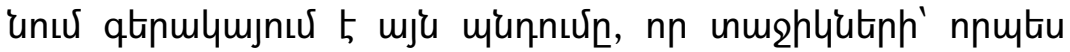

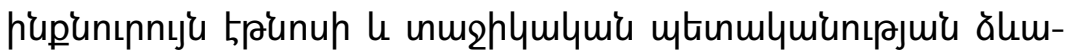

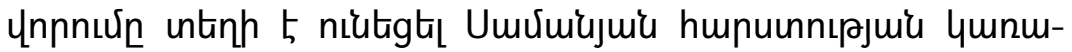

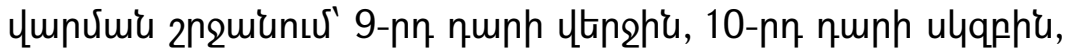

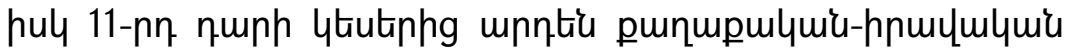

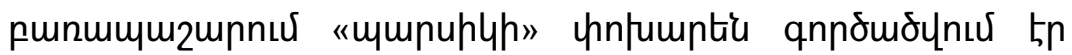

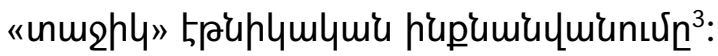

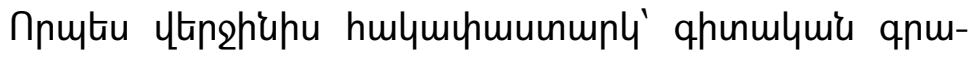

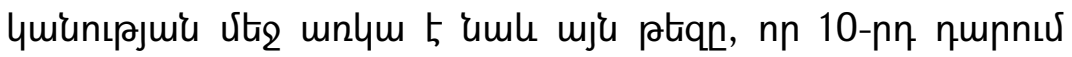

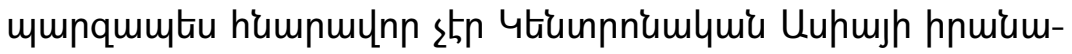

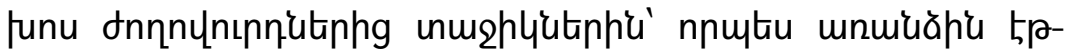

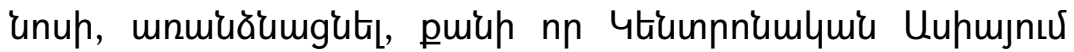

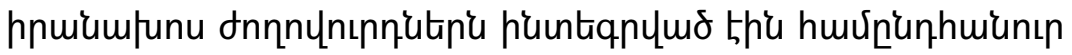

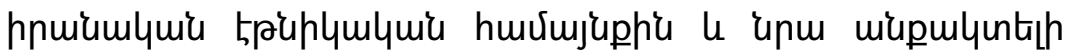
umue the ymqunnus:

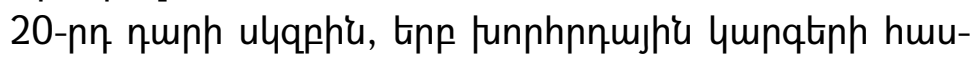

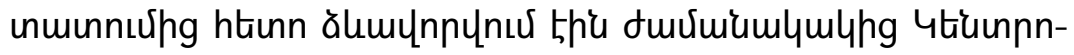

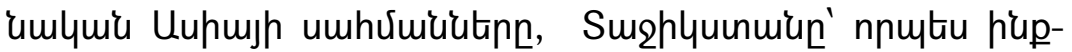

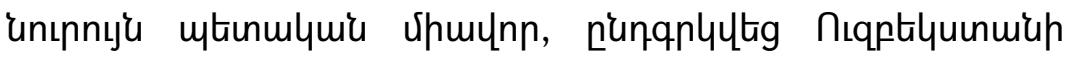

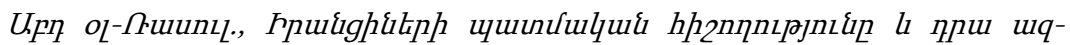

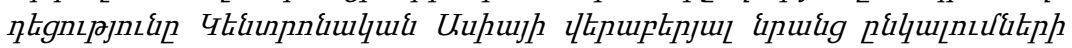

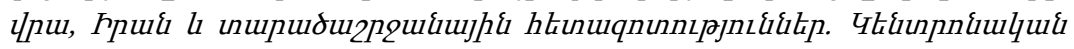
Uuhul, Othpuil, 2008, tq 51):

${ }^{3}$ Насурдинов Э. Трансформация правовой культуры таджиков и развитие её содержательных компонентов в рамках исламской цивилизации. Бизнес в законе. Экономико-юридический журнал, 2014, № 2, стр. 107.

${ }^{4}$ Bleuer Ch., Nouruzhanov K., Tajikistan: a political and social history, ANU E PRESS, 2013, p. 31. 


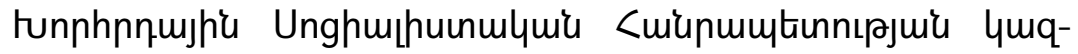
unus: Ctinmqu unuphiatiphé Sughlquinuiup' ntqptiquinuiup

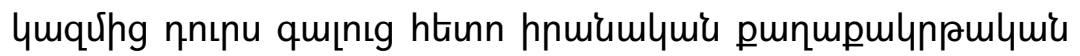

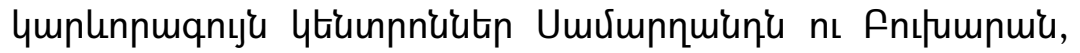

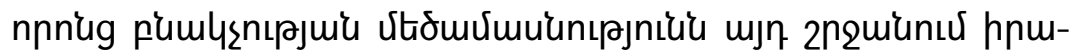

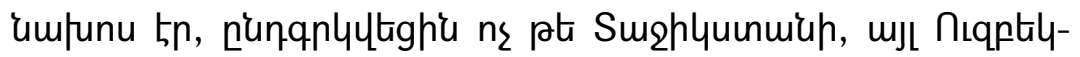

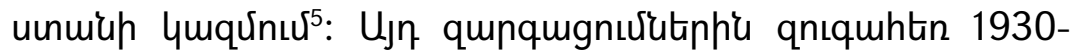

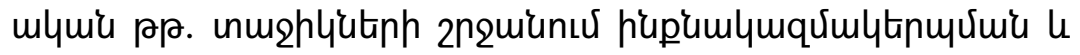

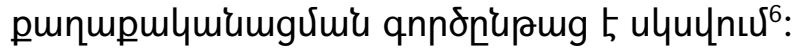

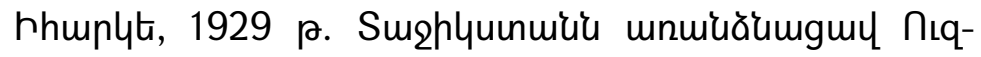

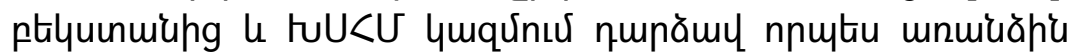

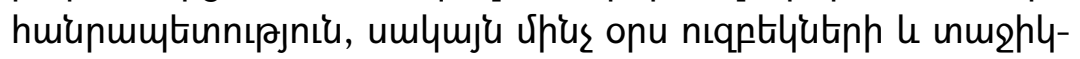

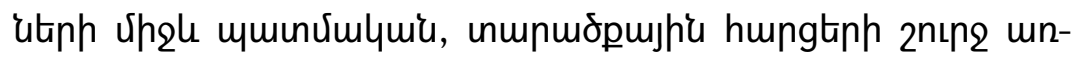

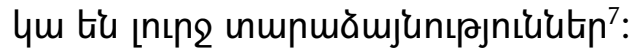

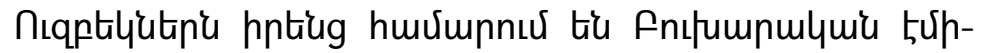

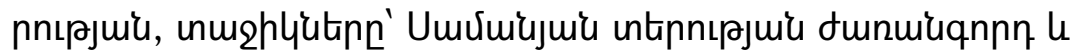

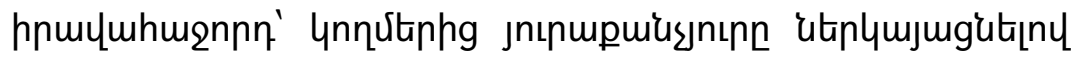

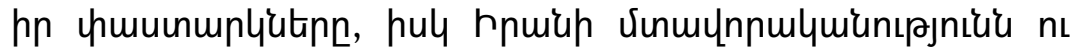

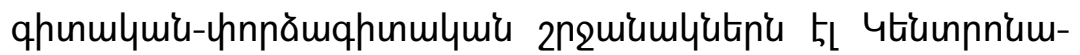

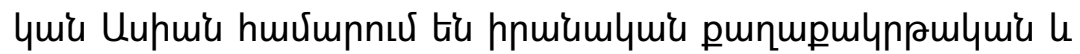

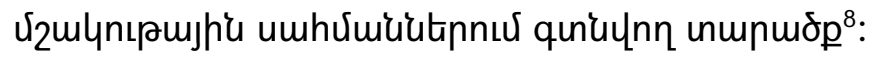

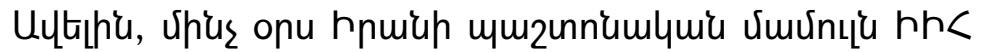

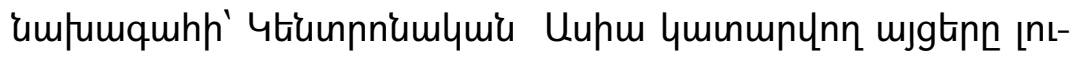

${ }^{5}$ Dagiev D., Regime Transition in Central Asia: Stateness, nationalism and political change in Tajikistan and Uzbekistan, New York 2014, p. 24.

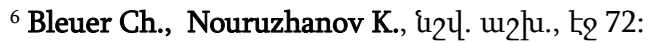

${ }^{7}$ Бжезинский 3. Великая шахматная доска (Господство Америки и его геостратегические императивы). Москва, 1998, стр. 159-160.

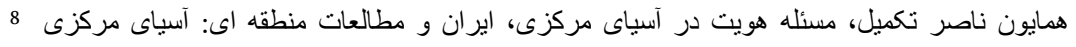

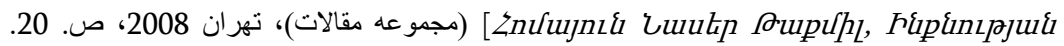

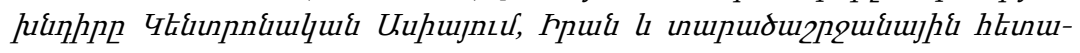

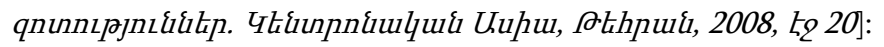




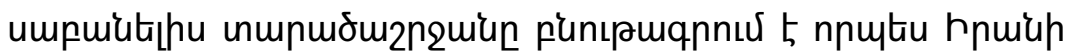

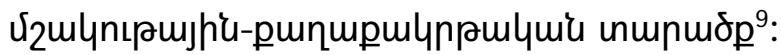

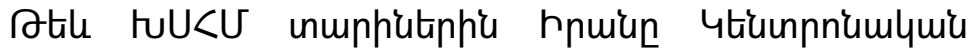

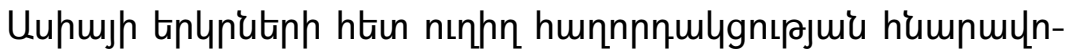

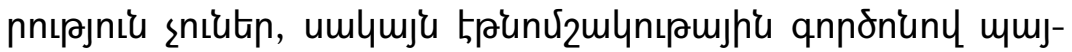

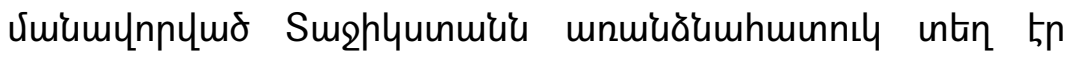

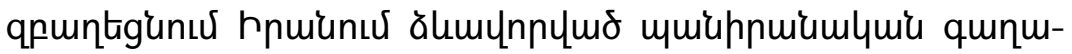

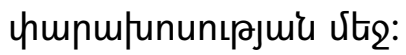

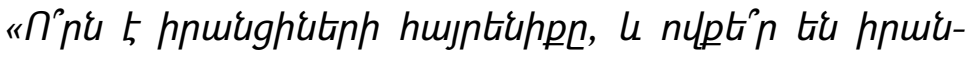

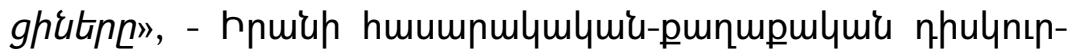

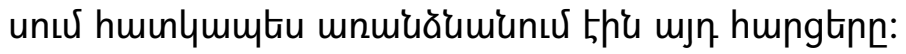

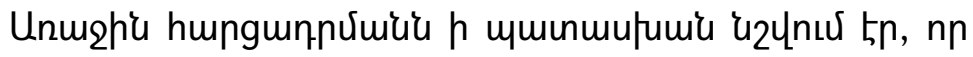
hnuiughutinh hujntiuhpn nunqnlynu 5 uju unupuroputinn,

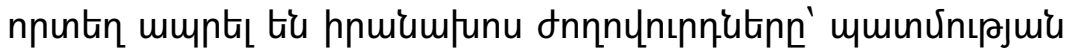

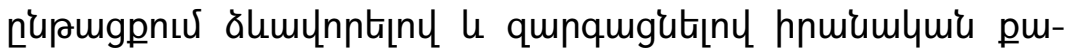

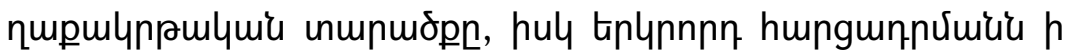

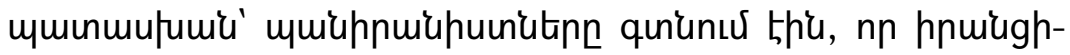

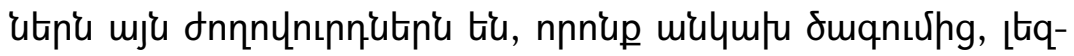

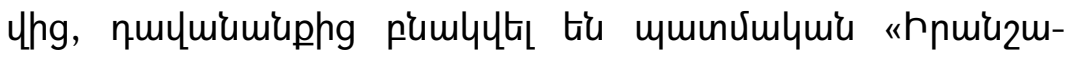
hpnuU ${ }_{1^{10}}$ :

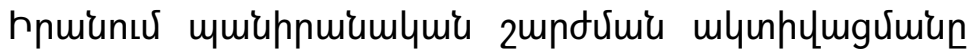

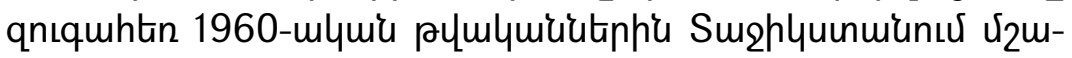

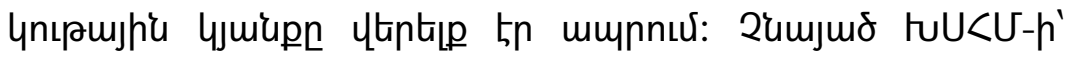

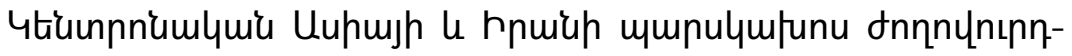

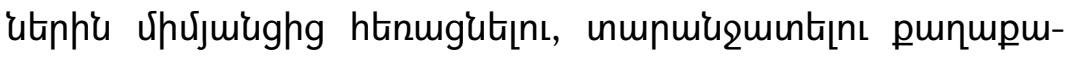

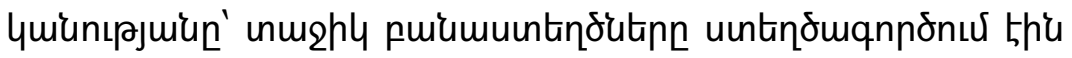

\footnotetext{
9 «Iran» newspaper, No: 6746, 03 April 2018, p. 3.

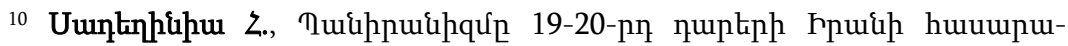

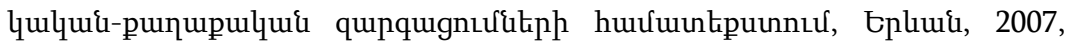
to 85:
} 


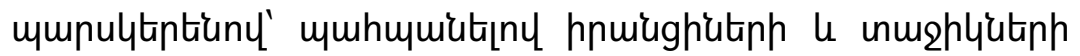

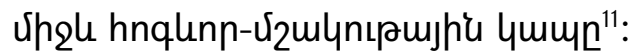

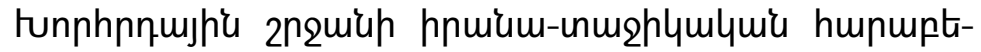

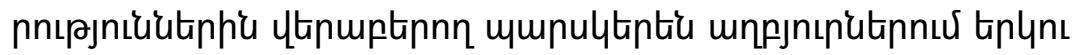

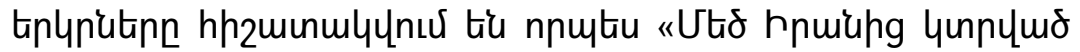
tiplns tiplnuúumutp ${ }^{12}$ :

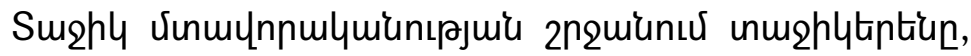

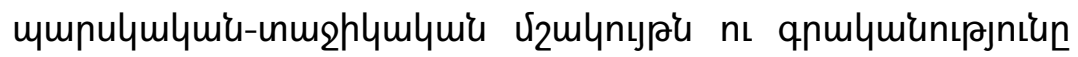

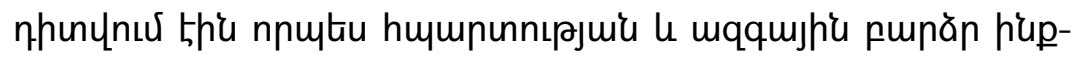

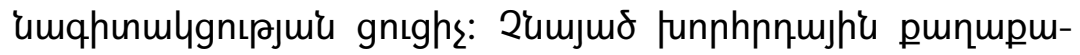

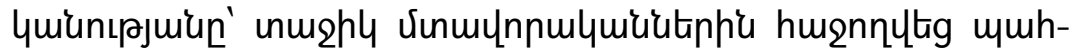

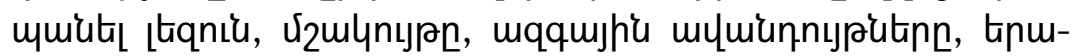

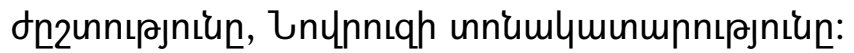

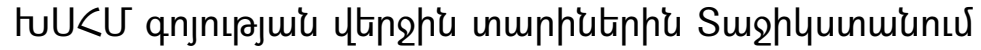

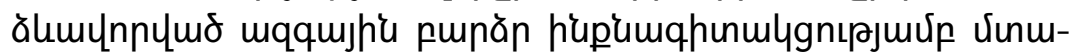

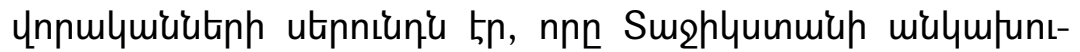

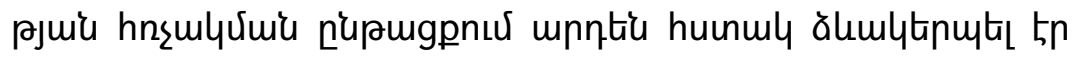

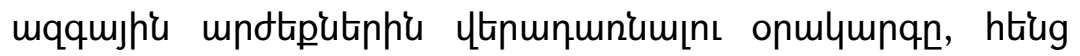

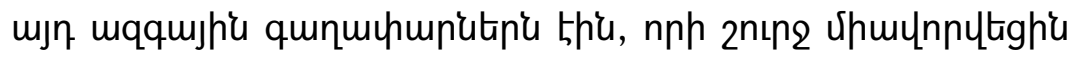
unupptin punupulymiu niotinn:

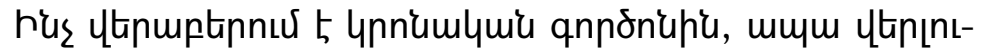

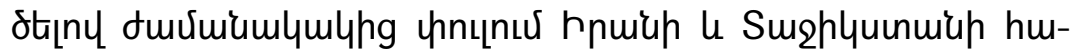

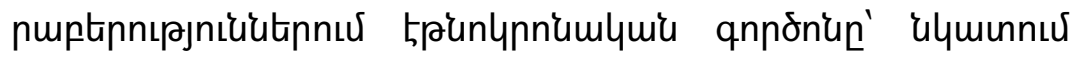

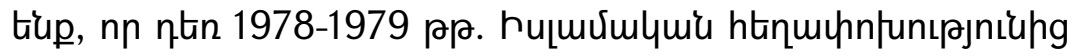

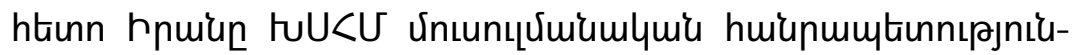

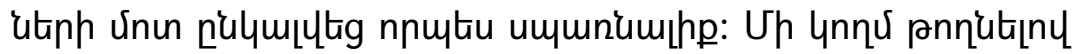

${ }^{11}$ Sinha M., The Persian World: Understanding People, Polity and Life in Iran, Afghanistan and Tajikistan, Hope India, 2015, p. 93.

محسن ملكيان، روابط فرهنكي ايران و ناجيكستان، مطالعات اور اسياي مركزي، 2012، شماره 11، 12

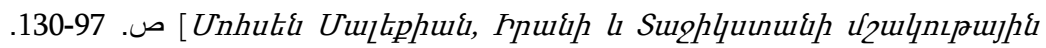

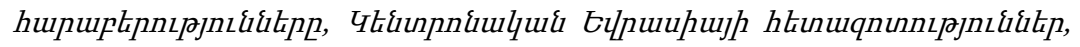
2012, 2. 11, tq 97-130]: 


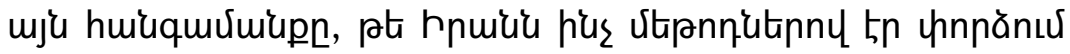

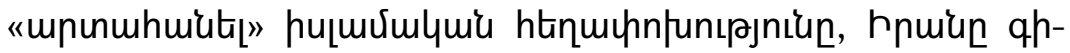

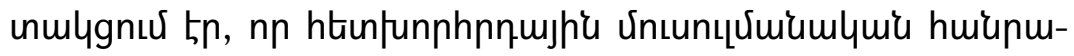

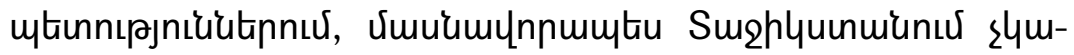

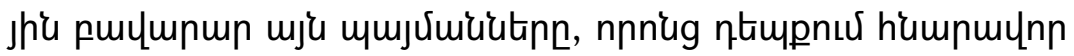

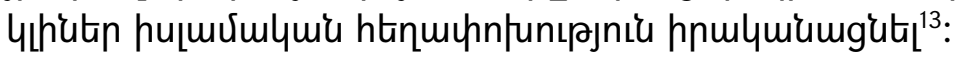

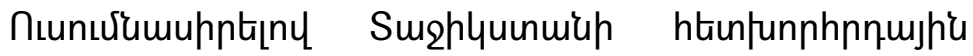

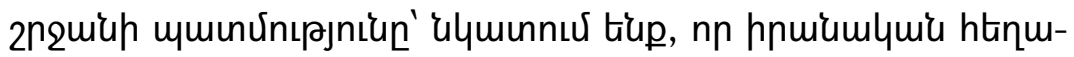

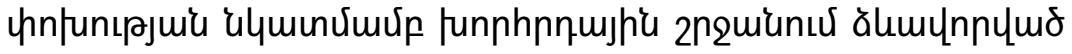

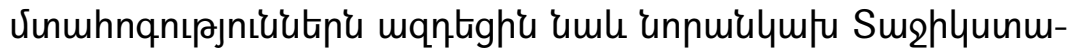

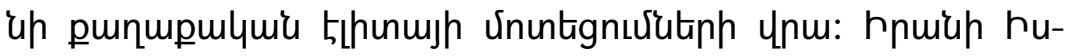

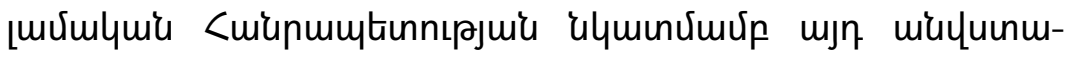

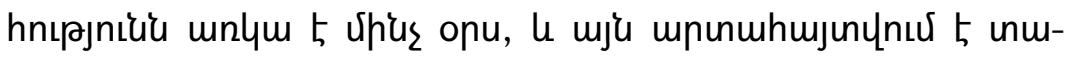
nuintiumly qnnonnnıرnıüutiph ungngnu:

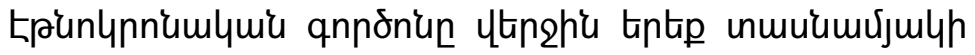

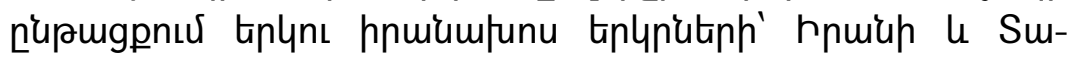

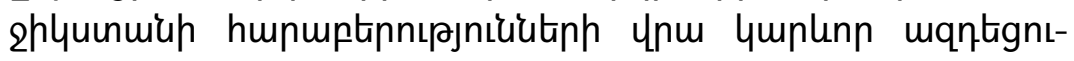

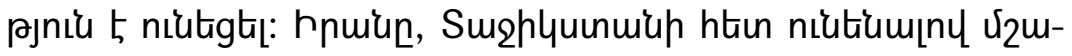

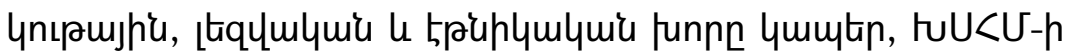

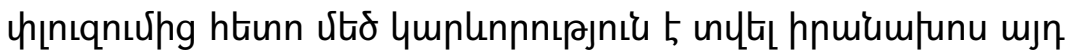

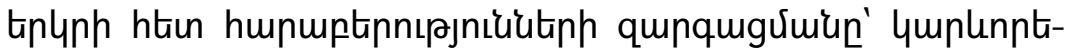

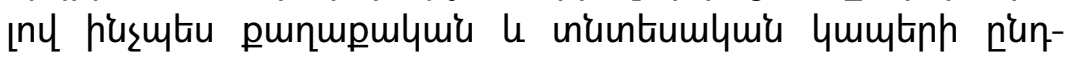

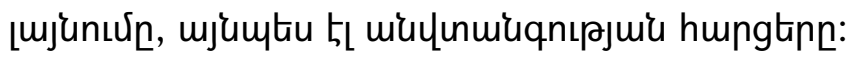

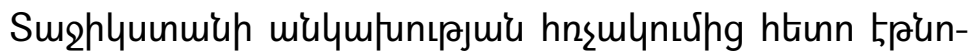

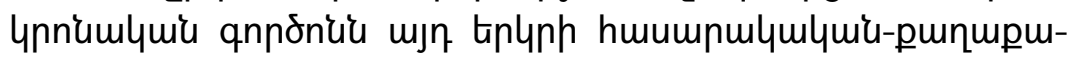

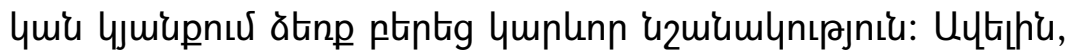

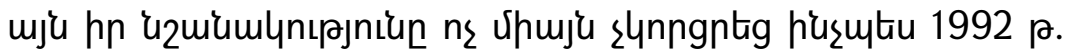

\footnotetext{
الهه كو لايى، ايران و روسيه در آسياى مركزى، ايران و مطالعات منطقه اى: آسياى مركزى (مجمو عها 13

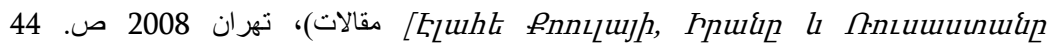

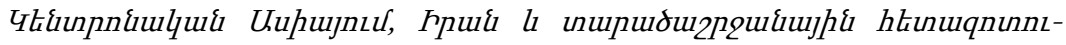

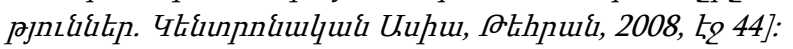




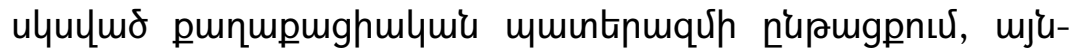

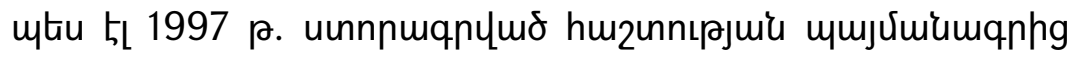

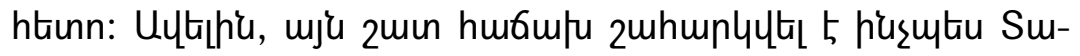

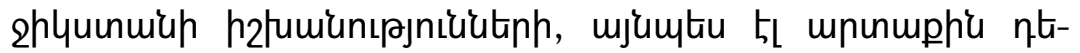

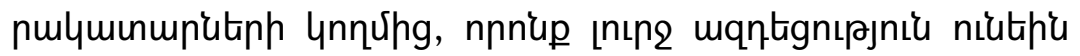

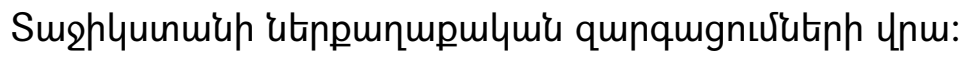

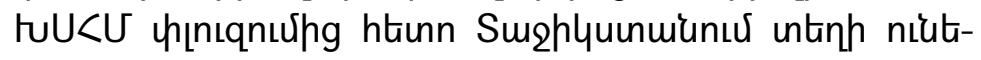

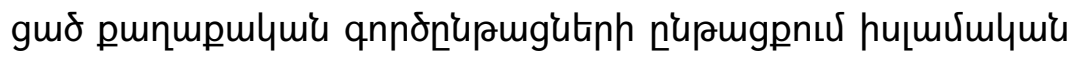

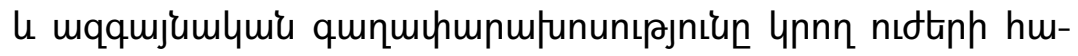

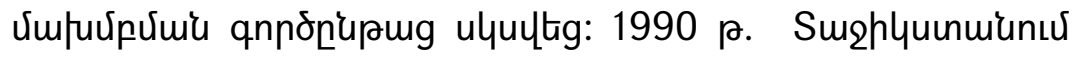

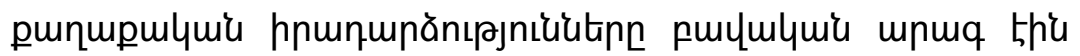

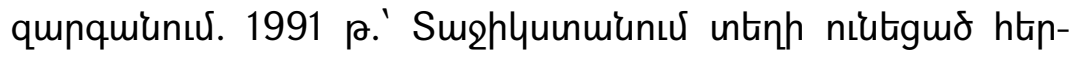
pulquir h2fumiumunfunıpjniuhg htiunn, tipn Sughluunuiuh

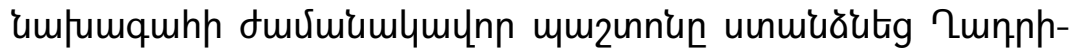

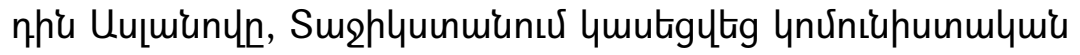

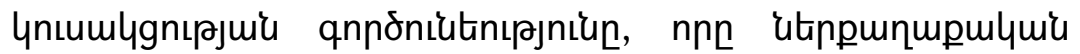

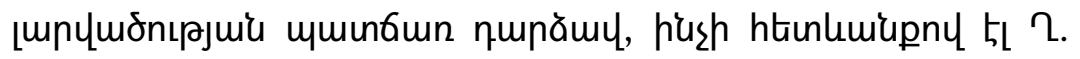
Uuguiunln hnuormpulywiu unltig:

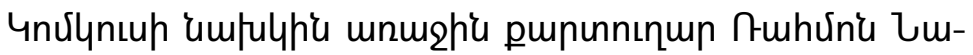

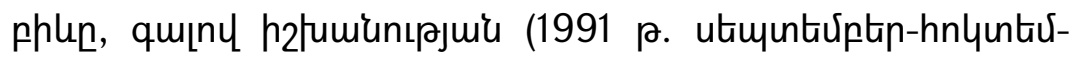

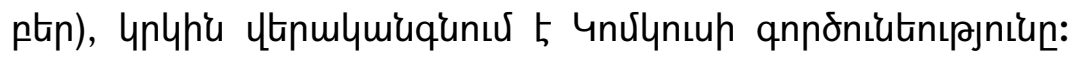

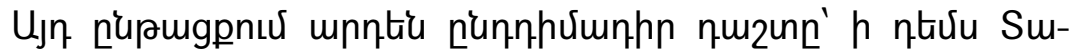

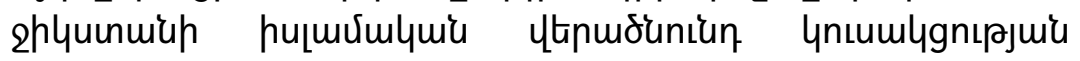

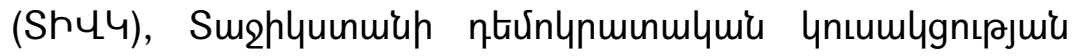
(S74) u "R-mupnfutq" (Ruppnup) ynıumlgnıрjuiu, thundtp

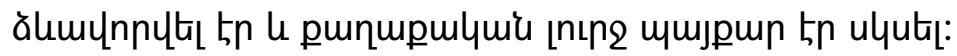

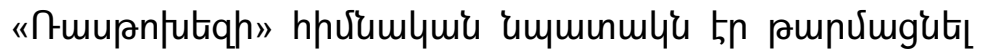

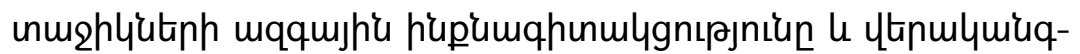

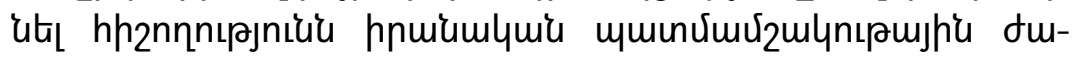

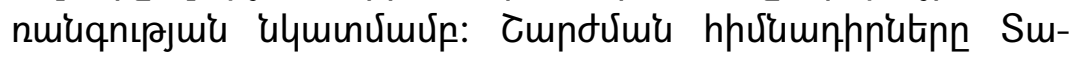

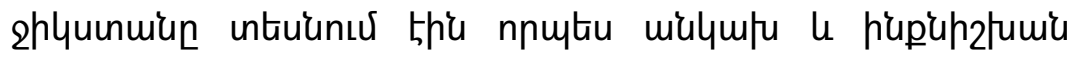




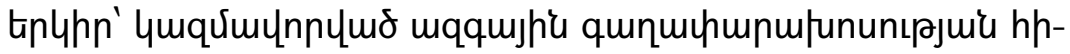
umiu \num $^{14}$ :

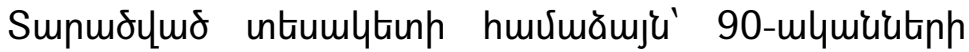

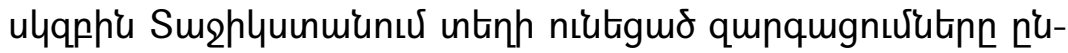

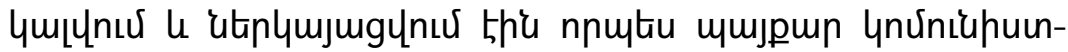

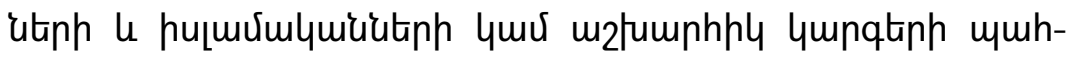

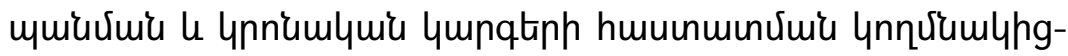
utiph unglu:

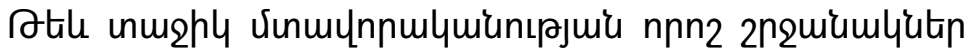

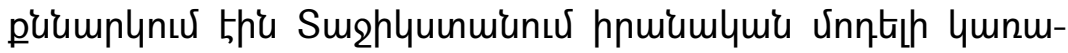

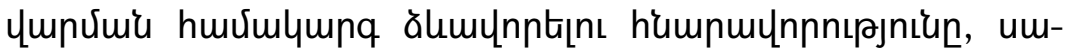

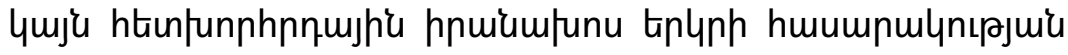

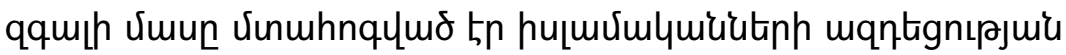

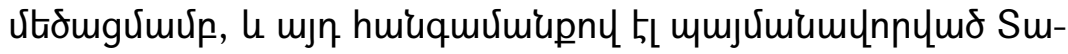

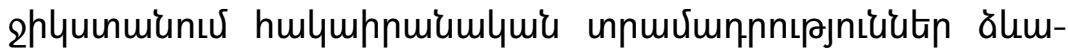
unnultghis'15:

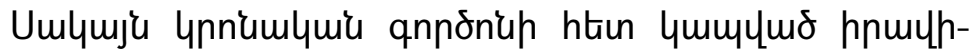

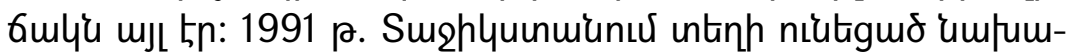

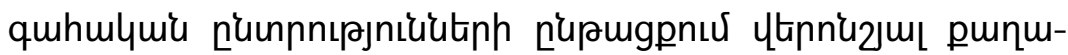

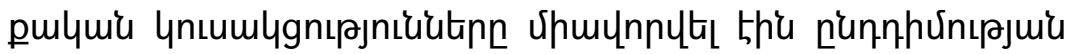

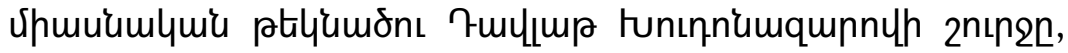
nnh ungulyhge tn nuhưnu lumphlen ${ }^{16}$ :

Chinmpnpnulymí 5, nn tunınuiamqunnylu unmqu-

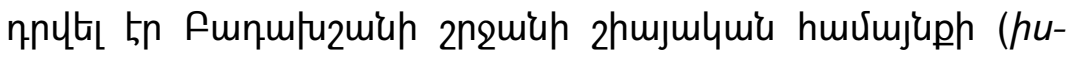

\footnotetext{
14 Epkenhans T., The Origins of the Civil War in Tajikistan: Nationalism, Islamism and Violent Conflict in Post-Soviet Space, Lexington Books, 2016, p. 50.

15 Санаи М. Взаимоотношения Ирана и Центральной Азии: Тенденции и перспективы. Москва, 2017, стр. 105.

${ }^{16}$ Karagiannis E., Political Islam in Central Asia, Routledge, 2010, p. 17-18.
} 


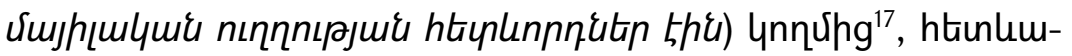

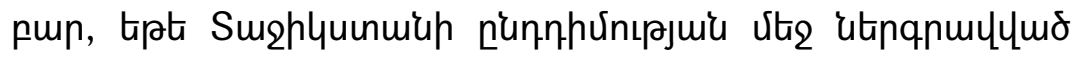

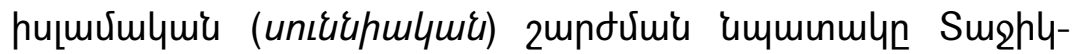

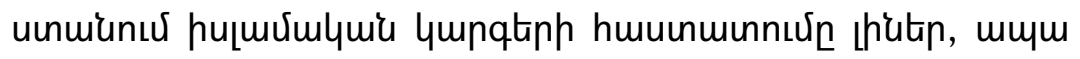

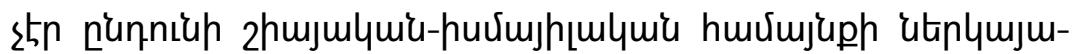

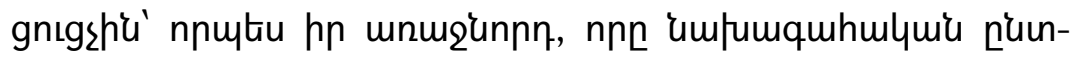

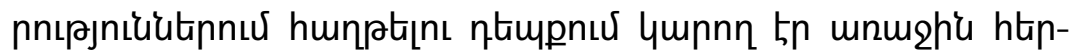

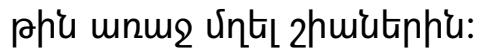

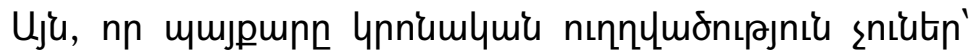

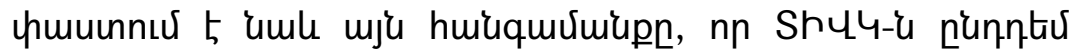

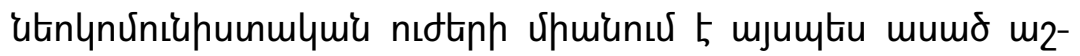

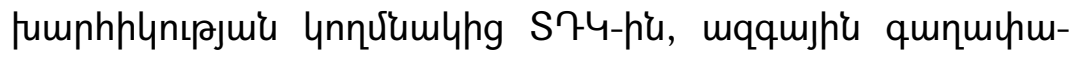

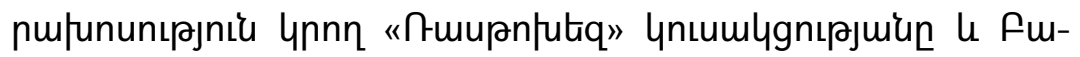

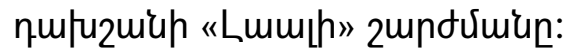

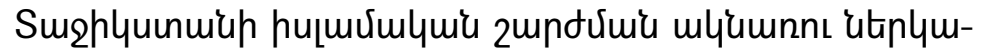

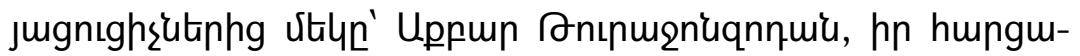

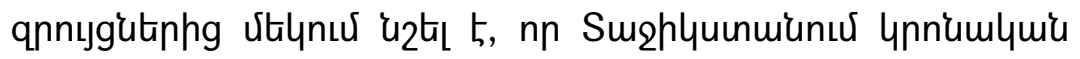

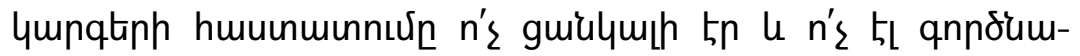

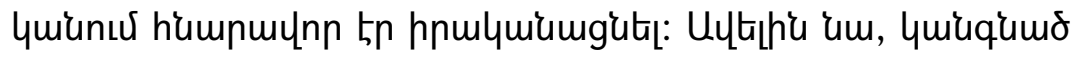

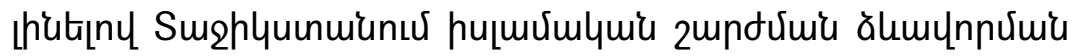

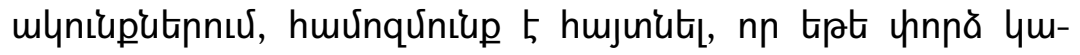

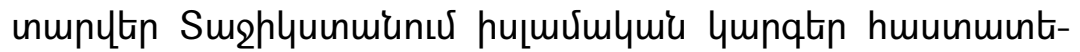

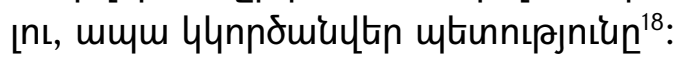

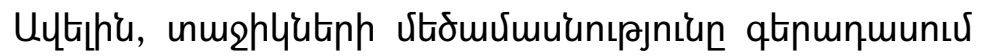

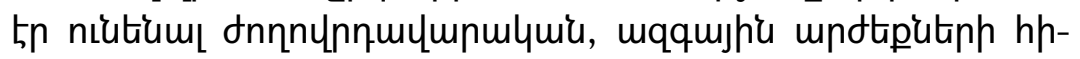

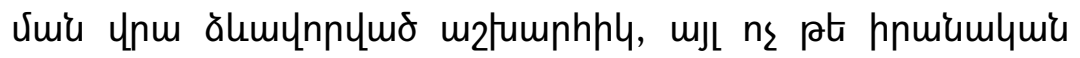

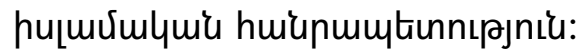

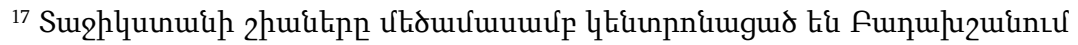

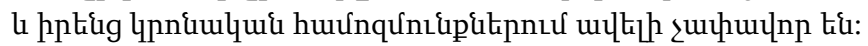

${ }^{18}$ Dagikhudo D., Regime transition in Central Asia, Stateness, nationalism and political change in Tajikistan and Uzbekistan, New York, 2014, p. 102.
} 


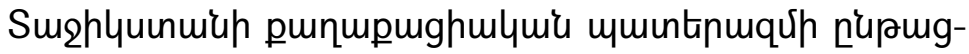

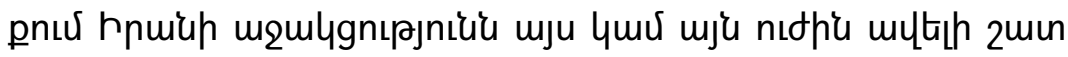

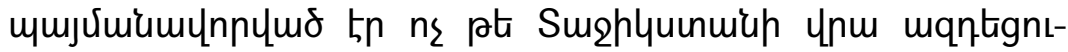

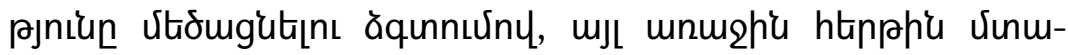

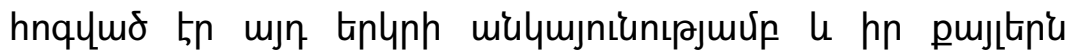

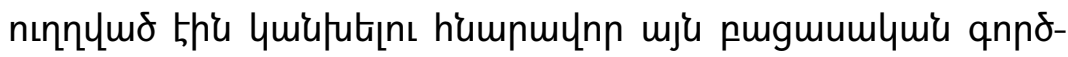

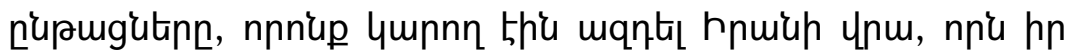

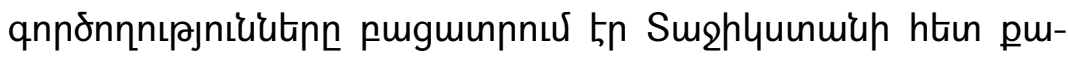

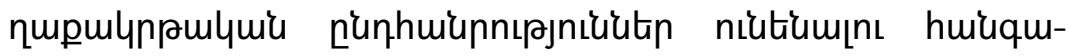
Umiupny ${ }^{19}$ :

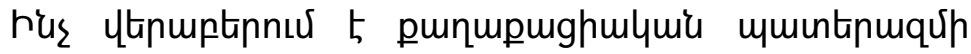

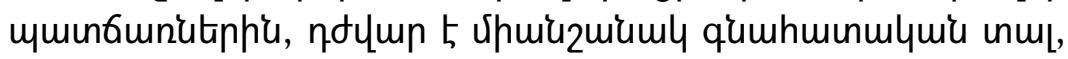

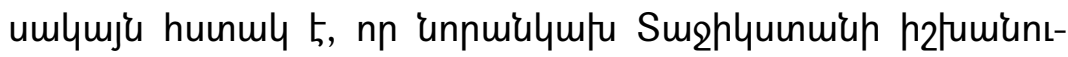

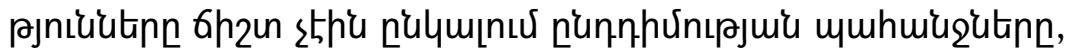

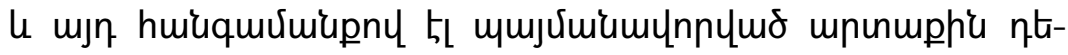

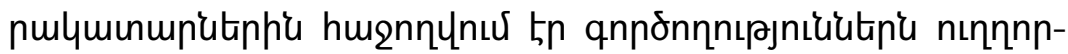

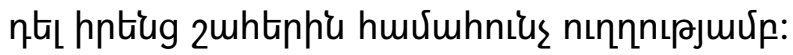

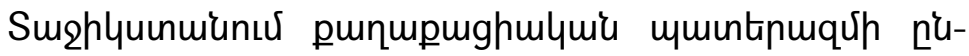

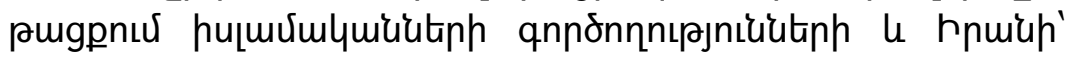

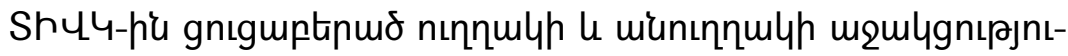

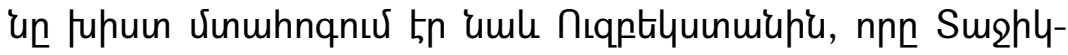

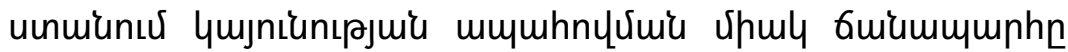

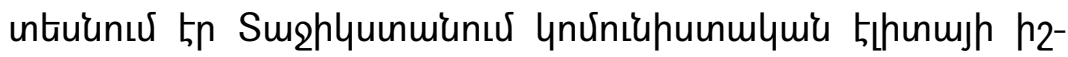

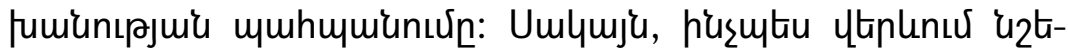

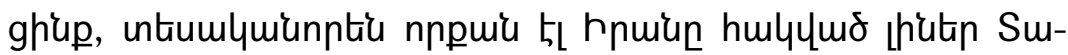

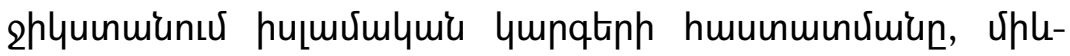

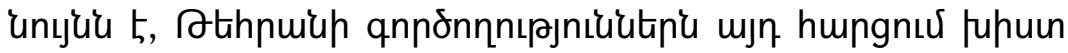
umhưumurum the'

\footnotetext{
${ }^{19}$ Dagikhudo D., \{12l. w2łu., tz 100:

20 Кулаи Э. Привязанность безопасности Афганистана и Таджикистана. Аму-Дарья, 2003, № 3, стр. 50-55.
} 


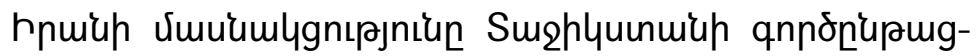

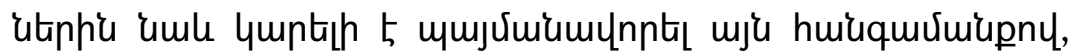

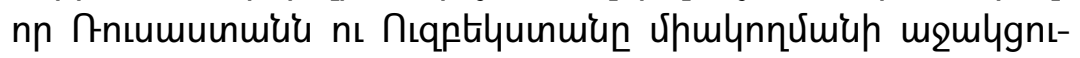

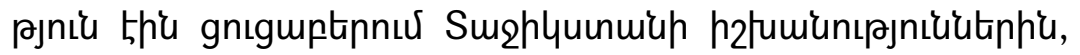

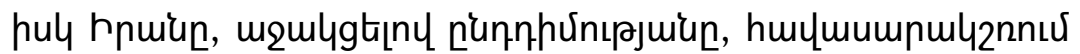
tn hnulh Gumln ${ }^{21}$ :

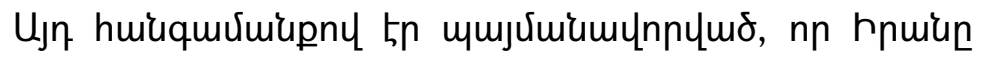

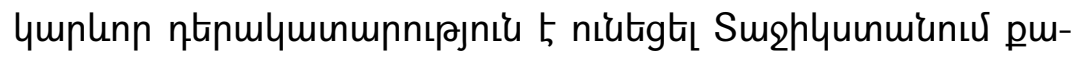

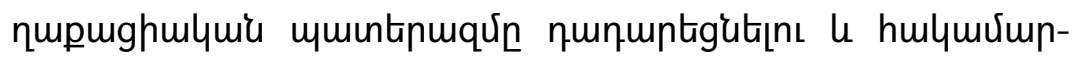

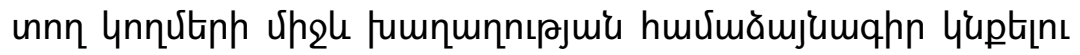

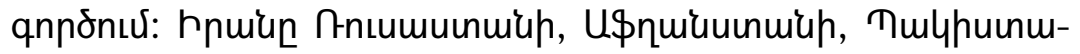

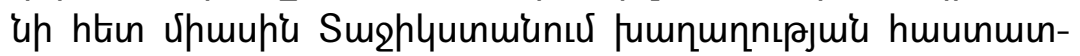

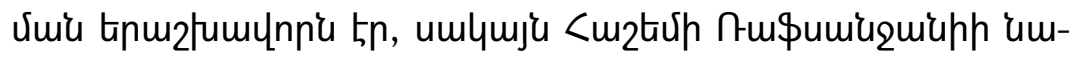

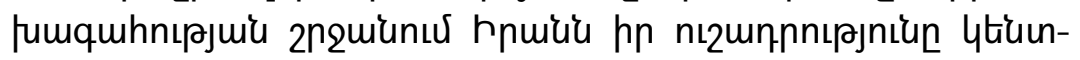

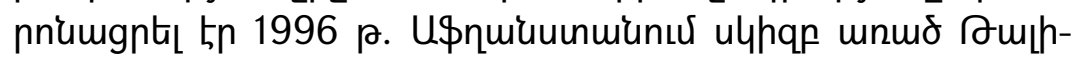

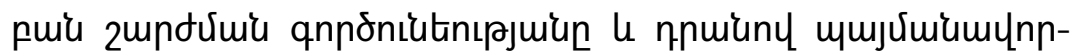

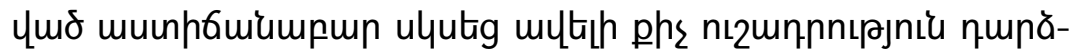
utis Sughluunmiahu:

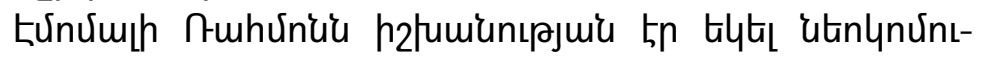

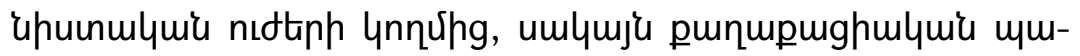

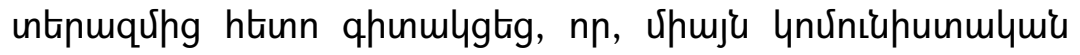

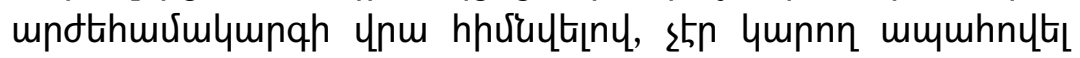

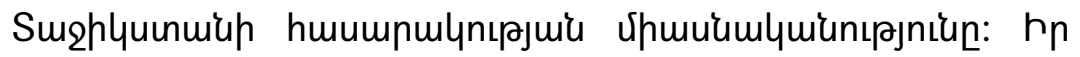

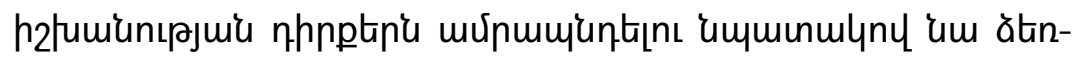

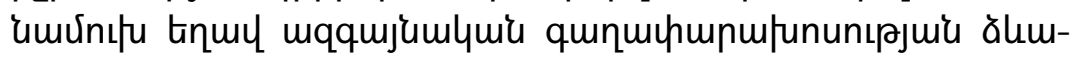

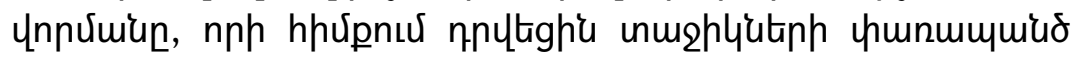

\footnotetext{
${ }^{21}$ Tasnim. 2017., رهبر نهضت اسلامى تاجيكستان :صلح تاجيكستان از دستاوردهاى مهم ايران انسان

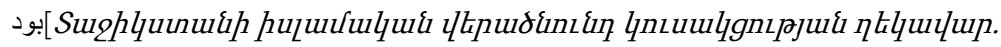

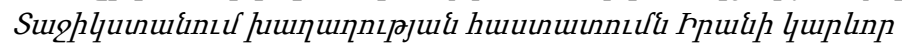
ànpptinnulitinhg hp], https://www.tasnimnews.com/fa/news/1397/03/30/1753872/ :
} 


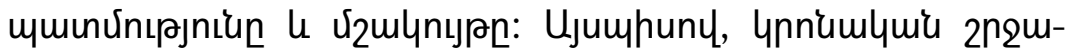

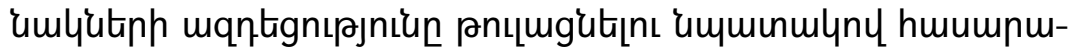

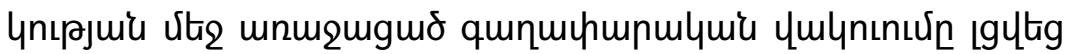

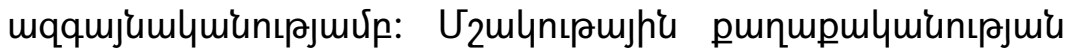

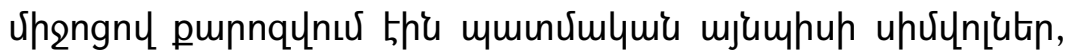

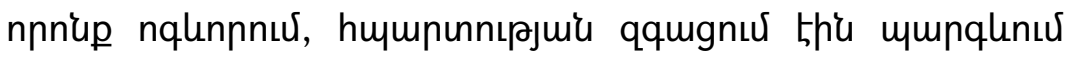

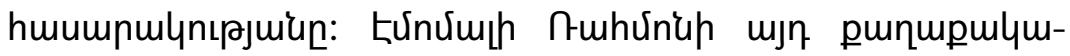

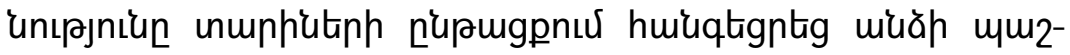
unuưniuph, tip Swghluunuiah qnnonn umfumquhn ulqutg

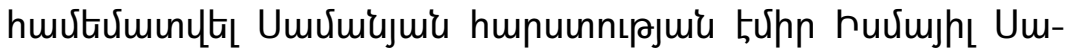
viuuph htiun 22 :

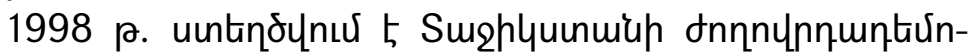

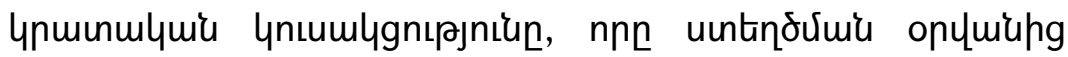

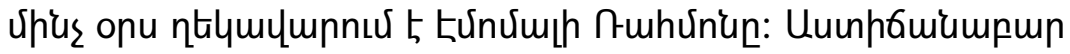

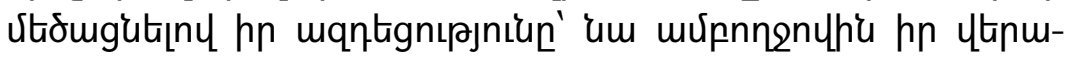

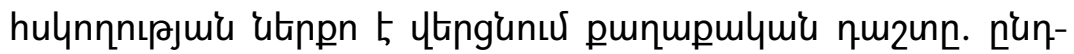

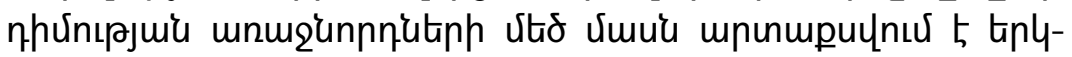

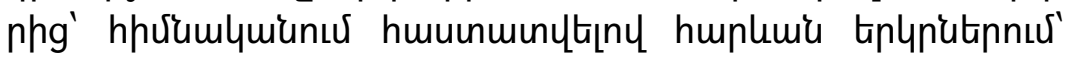

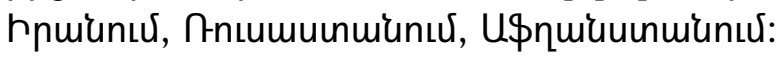

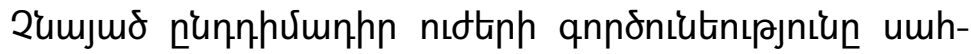

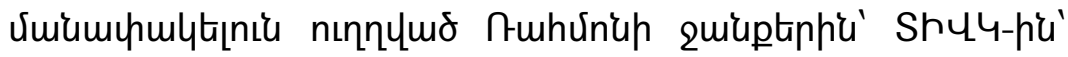

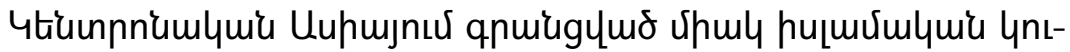

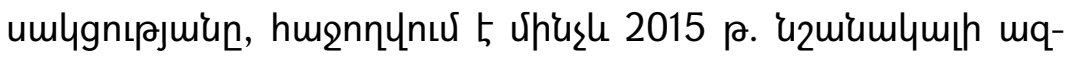

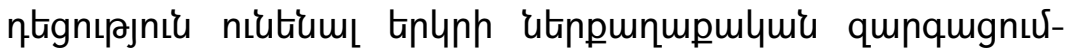

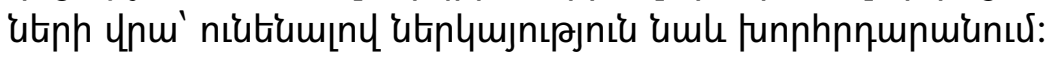

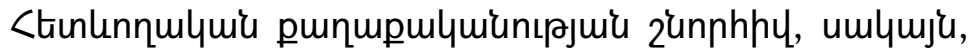

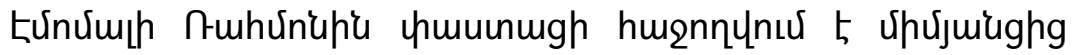

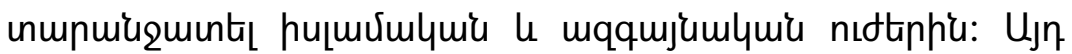

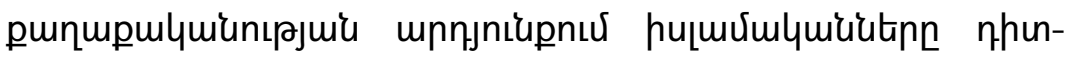

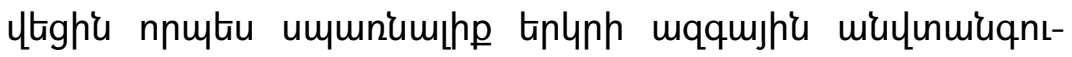

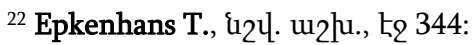


pjuiun, hul mje tenlnutinn, npnup hugurumlquilutiph htion

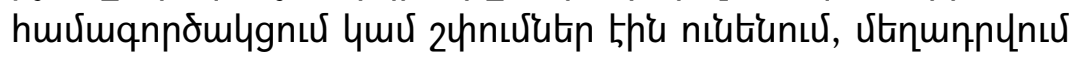

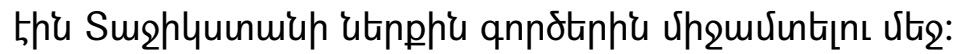

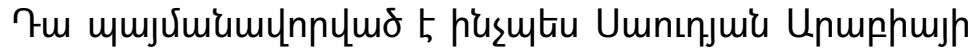

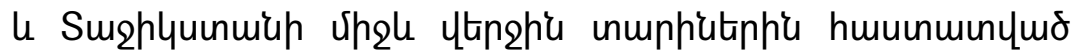

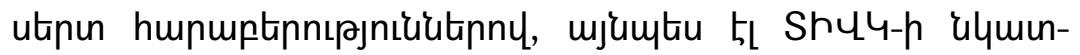

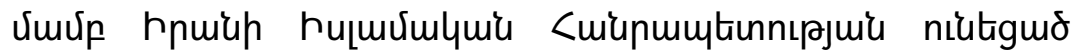
unnuqnnomugnıрjuй:

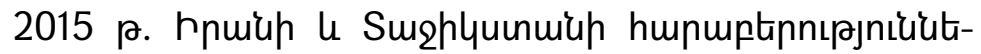

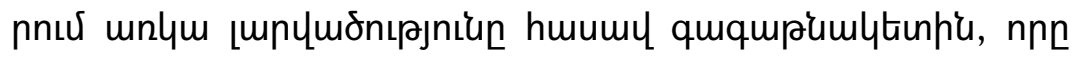

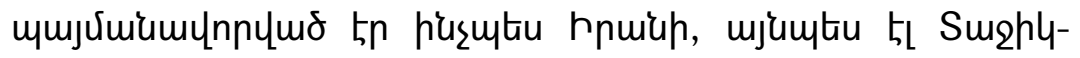

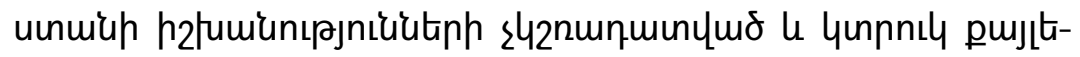
pny: 2015 p. hnuiunus untinh niutigmo «hu[uर्umlymu úpuru-

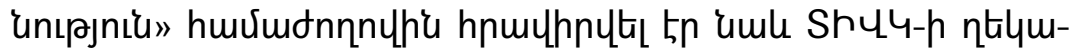

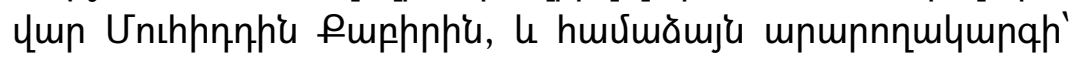

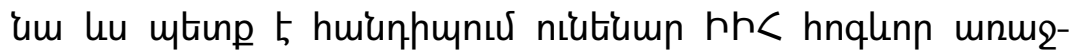

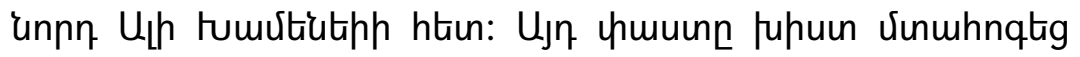

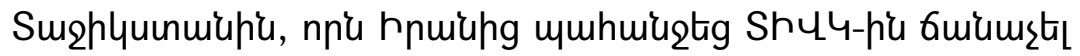

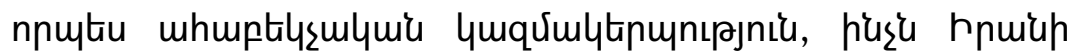

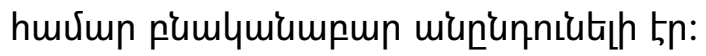

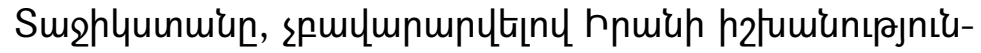

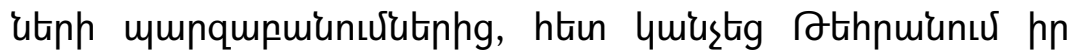

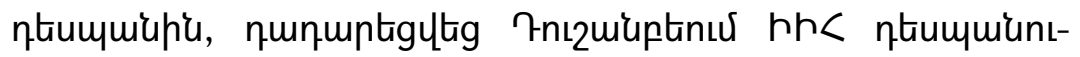

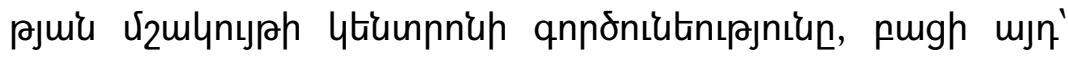

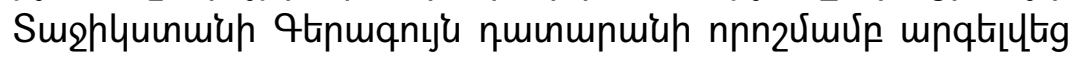

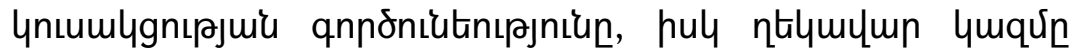
ătipnulymulltg'

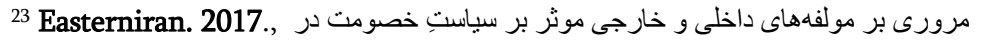

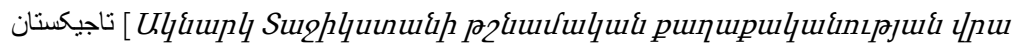

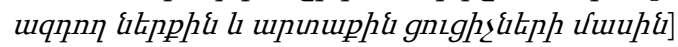

http://easterniran.com/fa/doc/analysis/906/:
} 


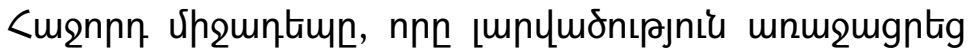

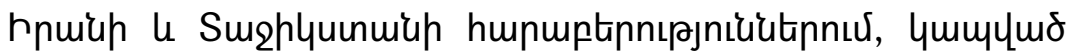

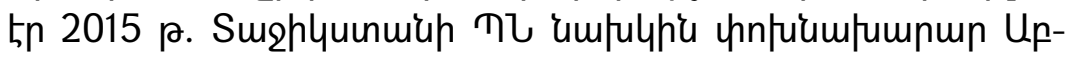

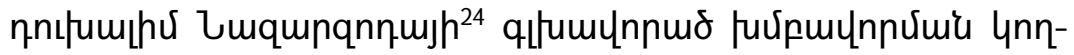

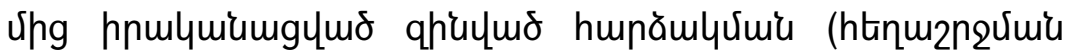

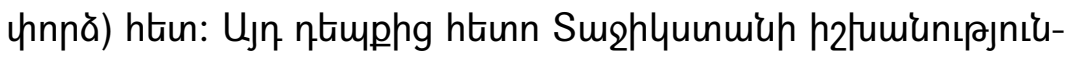

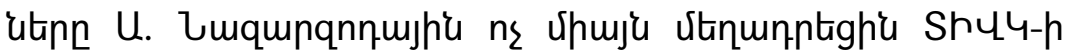

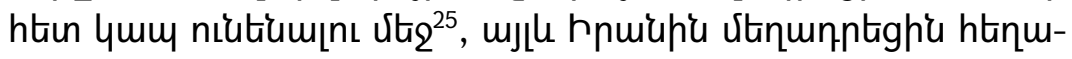

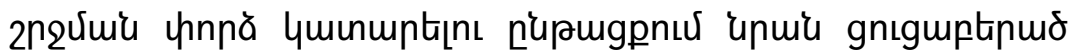

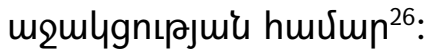

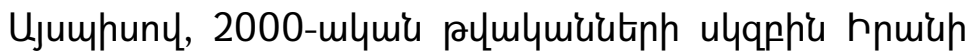

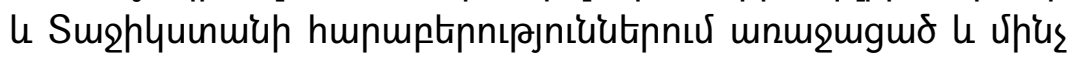

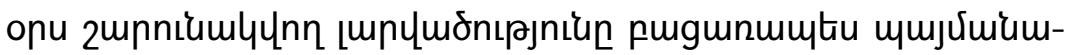

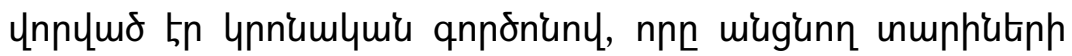

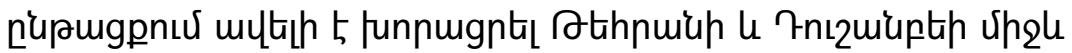

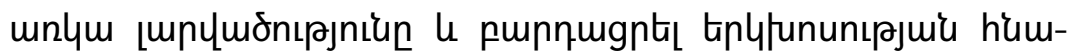
nuцLnnnıpjniun:

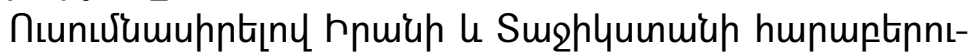

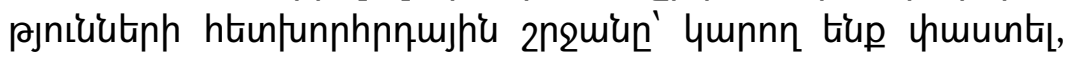

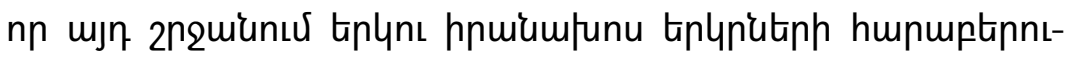

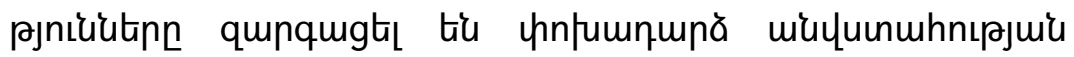

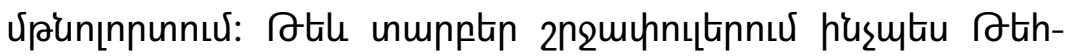

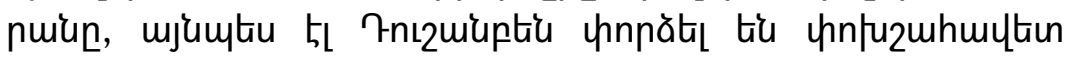

\footnotetext{
24 St' u News.tj. 2015., “Кем был беглый генерал? Биография Назарзода”, http://news.tj/ru/node/214229:

25 St'́ u BBC. 2015., “Таджикские спецслужбы убили мятежного генерала и его сторонников",

http://www.bbc.com/russian/international/2015/09/150916_tajikistan_general_ki lled:

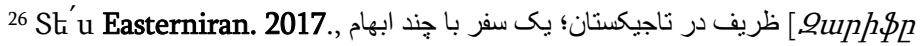

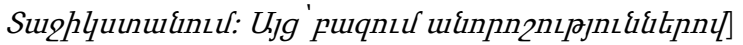

http://easterniran.com/fa/doc/analysis/1032/:
} 


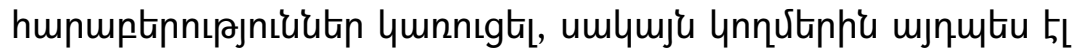

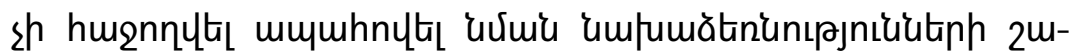
pniıulymumüunıpniun:

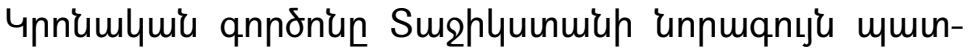

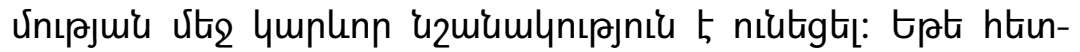

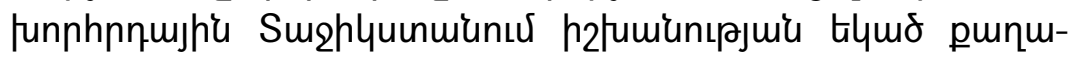

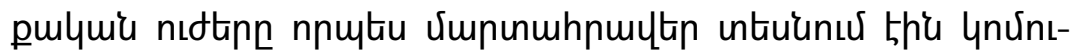

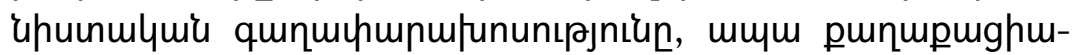

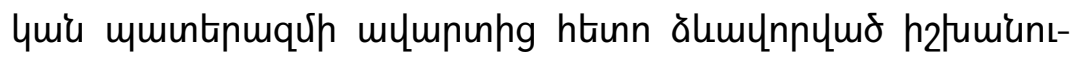

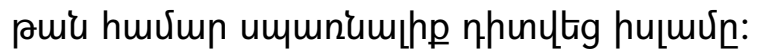

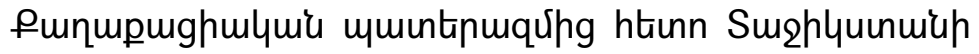

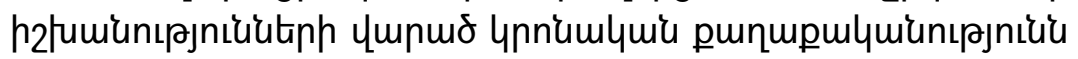

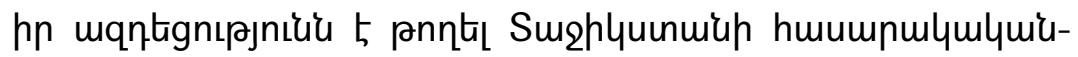

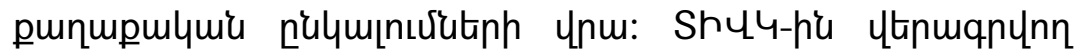

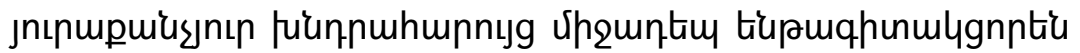

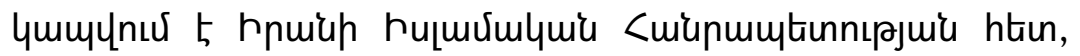

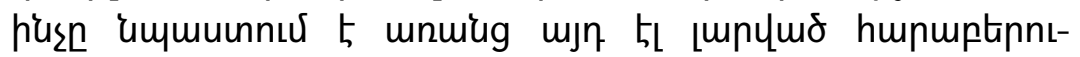

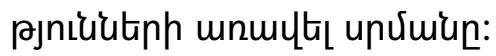

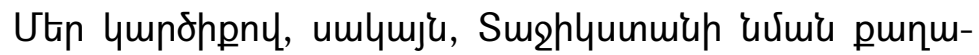

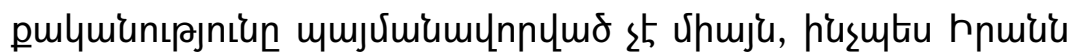

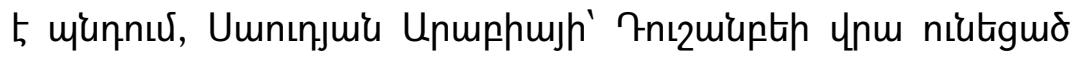

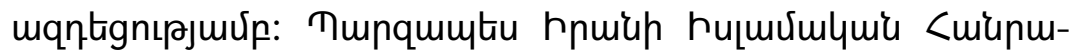

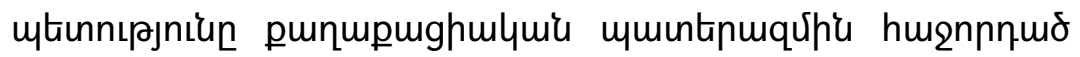

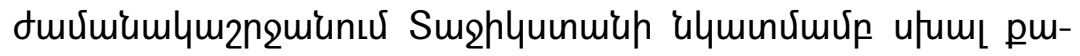

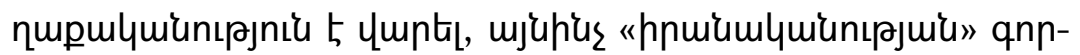

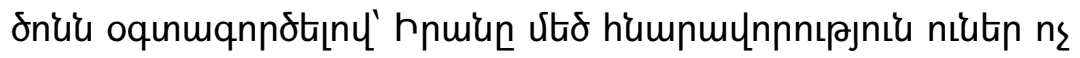

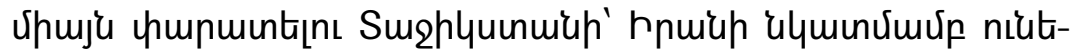

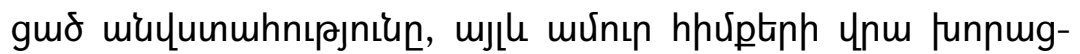

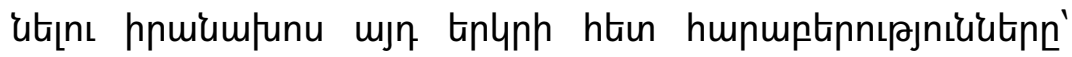

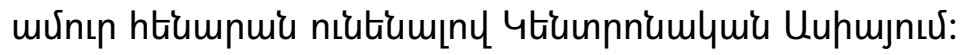




\section{ETHNIC AND RELIGIOUS FACTOR IN THE IRAN-TAJIKISTAN RELATIONS}

Keywords: Iran, Tehran, Tajikistan, Dushanbe, Uzbekistan, USSR, Central Asia, ethnic, religious, Relations.

During the last thirty years the ethnic and religious factor has had an important impact in the relations between two Iranian-speaking countries, for Iran and Tajikistan. Having cultural, linguistic and ethnic strong ties with Tajikistan, Iran attached great importance to the development of this Iranianspeaking country after the collapse of the USSR.

During the civil war in Tajikistan in the 1990s, Tajikistan was particularly important for Iran. The Islamic Republic of Iran is one of those countries whose immediate efforts made peace approved in this country after several years of civil war.

Heedless of the fact that after the collapse of the USSR relatively warm relationship was formed between Tehran and Dushanbe, thus after the civil war the relations between these two Iranian-speaking countries were developed in an atmosphere of mutual mistrust as a result of policy conducted both by Iran and Tajikistan. Even though in different periods Tehran and Dushanbe tried to build mutually beneficial relationships, the sides did not succeed in continuing such initiatives. 